\title{
Screening of Common Herbal Medicines as Promising Direct Inhibitors of Sars-Cov-2 in Silico
}

\author{
Zahraa Kamaz ${ }^{1}$, Mohammad J. Al-Jassani ${ }^{2^{*}}$ and Umar Haruna ${ }^{3}$ \\ ${ }^{1}$ Ioncure Tech PVT LTD. Delhi, India. \\ ${ }^{2}$ Department of Microbiology, College of Science, Al-Karkh University of Science, Iraq. \\ ${ }^{3}$ Department of Biochemistry, Federal University of Technology, Akure, Ondo State, Nigeria.
}

Authors' contributions

This work was completed upon collaboration of all authors. Author ZK performed analysis of pharmaceuticals features of used compounds such as oral bioavailability, Caco2 permeability, druglike value, drug half-life and toxicity and the coordinator of the manuscript, author ZK designed the docking study and did the molecular docking work and final draft corrections. Author UH designed $2 D$ log plots for all compounds using discovery studio visualizer software.

Article Information

DOI: $10.9734 / A R R B / 2020 / v 35 i 830260$ Editor(s):

(1) Dr. Paola Angelini, University of Perugia, Italy. (2) Dr. Viduranga Y. Waisundara, Australian College of Business Technology, Sri Lanka. Reviewers:

(1) Tanveer Hasan, Shia Post Graduate College, India. (2) Ahmed Neamah Ayyash, University of Fallujah, Iraq. (3) Angshuman Bagchi, University of Kalyani, India. Complete Peer review History: http://www.sdiarticle4.com/review-history/59980

Original Research Article

Received 20 July 2020

Accepted 04 August 2020

Published 11 August 2020

\section{ABSTRACT}

Background: Molecular docking has been used recently in pharma industry for drug designing, it's a powerful tool to find ligand-substrate interactions at molecules level. Since urgent need to develop anti-viral drug that target new coronavirus main proteins, in silico docking has been used to achieve this purpose.

Materials and Methods: Thirteen herbs are known for their antioxidants and antiviral properties have been selected to investigate their abilities in inhibiting SARS-COV2 spike protein and main protease Mpro. pdb files for RBD (Receptor Binding Domain) region of spike protein and for Mpro and $\mathrm{mol} 2$ files for all herbs understudy were uploaded for swiss dock online server, the docking results were analyzed using chimera software. Full fitness energy and hydrogens bonds interactions were considered for docking evaluation. Pharma kinetic properties for compounds have good binding results were evaluated through AMES and ADMET tests. 
Results: All compounds showed negative full fitness energy that means they are able to complex with both SARS-COV2 spike protein and main protease, however some of the herbs form very powerful hydrogen bonding with the RBD site of the spike protein and the catalytic site of Mpro such as coumarylquinic acid, while stigmasterol has strong binding with the spike protein only. Both compounds appear to be safe drugs for human according to AMES test results.

Conclusion: Coumarylquinic acid and stigmasterol have powerful binding in silico, further in vitro studies include using viral infected human lung cells and testing above compounds ability for inhibiting viral entry and replication should be proceed to confirm the study results.

Keywords: SARS-COV2; docking; COVID-19; spike protein; mpro inhibitors; natural herbs.

\section{ABBREVIATIONS}

$\begin{array}{ll}\text { SARS-COV2 } & \text { : Sever Acute Respiratory Syndrome Coronavirus } 2 \\ \text { Mpro } & \text { : Main protease } \\ \text { RBD } & : \text { Receptor binding domain } \\ 3 C L \text { pro } & : \text { BC like protease } \\ \text { ADMET } & \text { : Absorption, Distribution, Metabolism, Excretion and Toxicity } \\ \text { COVID-19 } & : \text { Coronavirus disease of } 2019 \\ \text { OB } & \text { : Oral Bioavailability } \\ D L & : \text { Drug Likeness } \\ H L & : \text { Drug Half Life } \\ T & : \text { Toxicity } \\ \text { CoVs } & : \text { Coronaviruses }\end{array}$

\section{INTRODUCTION}

Global emergency and pandemic have been declared by the World Health Organization for the new coronavirus disease (COVID-19) that cause outbreak all over the world. COVID-19 disease arises by SARS-CoV-2 infection causes symptoms like dry cough, fever, fatigue and pneumonia. As of now SARS-CoV-2 has reached 213 countries around the globe, with more than 17 million confirmed cases since March 18, 2020 [1]. This pandemic is still ongoing, so it is urgent to find new preventive and therapeutic agents as soon as possible. While specific vaccines and antiviral agents are the most effective methods to prevent and treat viral infection, there are not yet available treatments that target the 2019-nCoV. Development of effective vaccine can take years, meaning that more immediate treatment or control mechanism should be found if possible. Traditional Herbs used in medicine present a potentially valuable resource to this end.

As such, the Chinese government is encouraging the use of herbal plants in fighting this new coronavirus disease. However, the application of herbal treatment is mainly guided by the type of herb (based on the catalogue of classic literature on herbs) and the patient's symptoms or signs. There is insufficient information to predetermine whether the herbs in question can directly target the virus cause disease or relief virus accompanied symptoms, in other words, herbal usage is generally not guided by viral pathology. We think more detailed information about antiviral effects of different plants would be greatly helpful for doctors in selecting them. In fact, after the outbreak of SARS, many research groups dedicated themselves to find anticoronavirus agents, including some natural compounds that exist in traditional Chinese herbal medicines [2-10]. Coronaviruses encodes more than one dozen proteins, some of which are essential to viral entry and replication. Among these proteins, the most well-studied are spike protein and $3 \mathrm{C}$-like protease (3CLpro). The spike protein of CoVs binds to a host cell membrane through a receptor-mediated interaction which allows entrance to the host cell. It has been determined that the SARS-CoV-2 has similar mechanism to that of the SARS virus in the way of cells entry and the receptor to which it has the highest affinity is ACE2 (angiotensin-converting enzyme 2) [11]. While there are structural similarities between the SARS-CoV-2 spike protein and the SARS spike protein, the conservation is only $73 \%$ with most of the variability being in the host cell interaction region of the protein. Coronavirus SARS-3CLpro is a cysteine protease indispensable to the viral 
life cycle, it cuts transcribed long polyproteins into replicase enzyme and other structural proteins [12]. These two proteins are attractive targets for drug development. For the study of medicinal plants and their bioactive compounds, in silico ligands docking coupled with network pharmacological profiling is getting more concerns by providing valuable information for proteins' targets as well as their mechanisms of action, and development of new computational methods for drug discovery and drug-target validation on chemical and pharmacological levels [13-18].

Through in silico docking and the compounds safety tests, a series of small molecules, including those from natural compounds, have been screened and confirmed to directly inhibit these important proteins in SARS and Middle East respiratory syndrome (MERS) coronavirus [19-25]. The gene sequence of 2019-nCoV has been released, currently there are $>100$ complete genome sequences known in the NCBI GenBank from over 10 countries. The variation between these sequences is less than $1 \%$. This virus is closely related to the SARS-CoV which allows utilization of known proteins structures for SARS-CoV as templates to quickly build a model for the purpose of drug discovery on this new SARS-CoV-2 [26-28].

It is challenging to screen out all the herbs that might contain anti-coronavirus (2019-nCoV) compound(s) especially in a very short time. In the current study, we have screened the most common and available traditional herbs through implementing these methodologies in an attempt to identify the most effective and safe compound(s).

\section{MATERIALS AND METHODS}

The approach is taken here to search possible medications for the SARS-CoV-2 by performing in silico docking models from the most variable proteins in the SARS-CoV-2, the spike glycoprotein, and the SARS-CoV-2 3CL main protease. Both spike and protease proteins are essential for the transmission and virulence of the virus. However, inhibiting anyone of these two proteins or both for a higher active therapy, the severity of the infection will be reduced. Our efforts have been placed in competitively inhibiting the binding of its natural substrates. Main bioactive compounds of the most common herbs have been run against several sites on the spike protein (RBD) and the catalytic site of the
SARS-CoV-2 main protease represented by residues HIS41 and CYS145, distance between the two residues is $3.8 A^{\circ}$ [29].

Different herbs that are commonly used as antioxidant, antiviral and for the treatment of respiratory tract infections and their complications were selected. Total of 13 main natural compounds constituents were examined for structure chemical and therapeutic properties (https://tcmspw.com, https://pubchem.ncbi.nlm.nih.gov).

\subsection{Protein-molecular Docking}

The crystal structure of the spike protein RBD site (6w41) and main protease (6m03) (https://rcsb.org) were used for docking test, 3D structure for each tested compounds is obtained from pubchem website (https://pubchem.ncbi.nlm.nih.gov/), receptors (RBD of spike protein and $3 \mathrm{CL}$ pro and ligands are prepared for docking using Chimera software (version 1.14). Docking was accomplished through the online Swissdock software/ server (http://swissdock.ch/ [30]. Less Full fitness score for ligand pose, number of hydrogens bonds and other binding forces were employed as parameters for prediction good docking results. UCFS Chimera

(http://www.cgl.ucsf.edu/chimera), a molecular visualization tool, was used to visualize the results obtained from the server [31]. PyMOL (version 1.3) and BIOVIA Discovery Studio 2016 was further used to prepare the 3D protein-ligand complexes and 2D interactions of the complexes.

\subsection{Pharmacokinetic Properties}

It is faster and more economical to screen active chemicals using ADME-T (absorption, distribution, metabolism, excretion and toxicity) models simulated in silico systems [32]. Caco2 permeability, oral bioavailability (OB), druglikeness (DL), half-life $(H L)$ and toxicity $(T)$ were used to apply ADME-T-related models. The screening was done for the most efficient natural compounds since these herbal treatments are bioactive via oral administration. The tested ligands are coumarylquinic acid, hexadecanedioic acid, quercetin and stigmasterol. The indices used for the screening include evaluation of oral bioavailability, Caco-2 permeability, drug-like value, drug half-life and toxicity. Smiles formats for each of the fourth compounds were obtained from PubChem website (https://pubchem.ncbi.nlm.nih.gov/). 
ADMET properties for the compounds were evaluated using ADMETSAR online server (http://Immd.ecust.edu.cn/admetsar2/)

The threshold values indicating effectiveness for these four indices were $>30 \%,>-0.4,>0.18$ and $>3 \mathrm{~h}$, respectively, as recommended by $[33,34]$.

\section{RESULTS}

Molecular docking is a very powerful tool to investigate the possible treatments for ncov19 since it's time consuming and vaccine developing will take at least about $12-18^{\text {th }}$ months to be marketed. However, another quick approach is to find the suitable medicine against the virus by applying computational predicted inhibition.
Thirteen compounds known as herbs have been selected as potential inhibitors of SARS-COV2 spike protein and main protease. Some docked compounds showed the highest affinity to bind with both spike RBD (Fig. 1) and main protease activity site represents by HIS41 and CYS141 (Fig. 2).

Four ligands have highest negative fitness energy and form more conventional hydrogens bonds with SARS-COV2 proteins which mean a longer residence time at the binding site except for Stigmasterol that gives weak binding with the main protease. (Fig. 3).

The binding forces represent by Van der walls, $\mathrm{Pi}$ Alkyl, Carbon hydrogens bonds and pi-pi stacked are executed using 2D plots (Fig. 4 and Fig. 5).

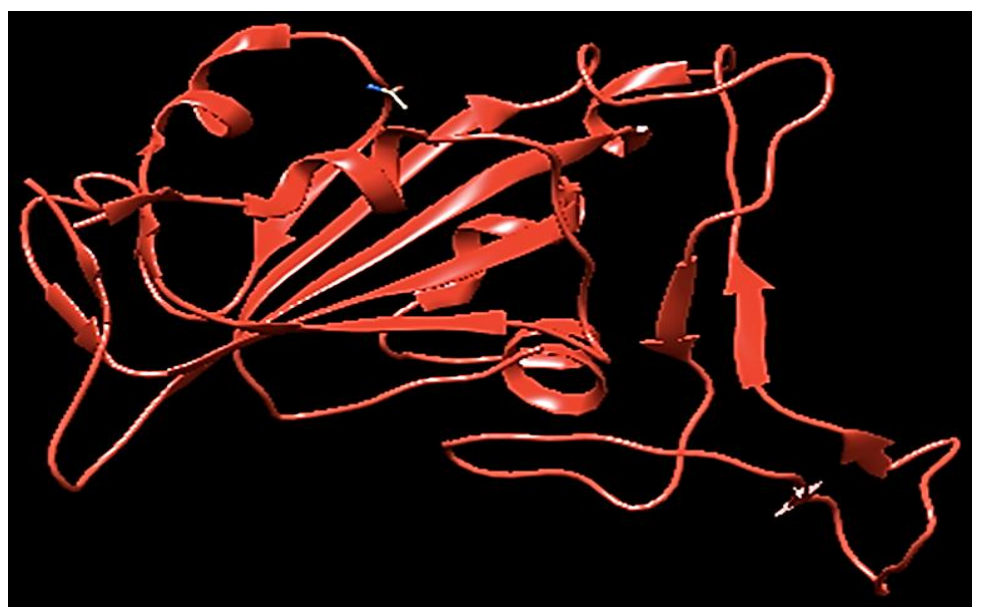

Fig. 1. Spike protein chain $C$ represents the (RBD) that consist of 231 residues

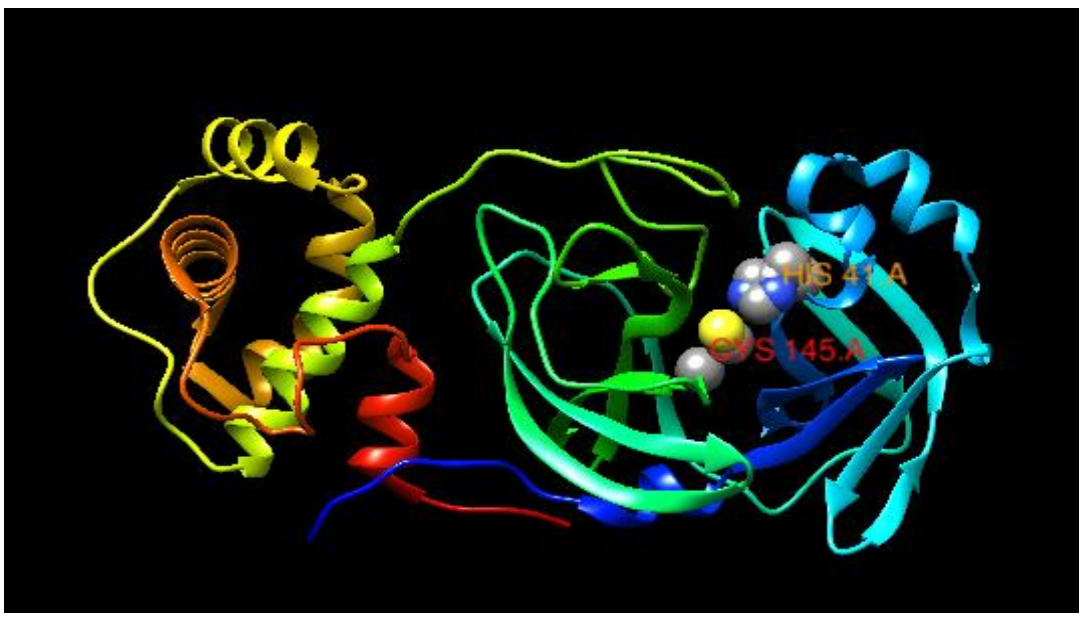

Fig. 2. Main protease of SARS-COV2, catalytic site is located between two residues HIS41 and CYS145 
Full fitness energy and $\Delta G$ energy for all compounds binding with SARS-COV2 spike protein and main protease are listed in Table (1). Coumarylquinic acid has bound with RBD protein by forming two hydrogens bounds with CYS 336 residue and 1 hydrogen bound interaction with 339 GLY residue (Fig. 3A) while it hits main protease activity site residue HIS41 with one strong hydrogen bound binding (Fig. 3B).
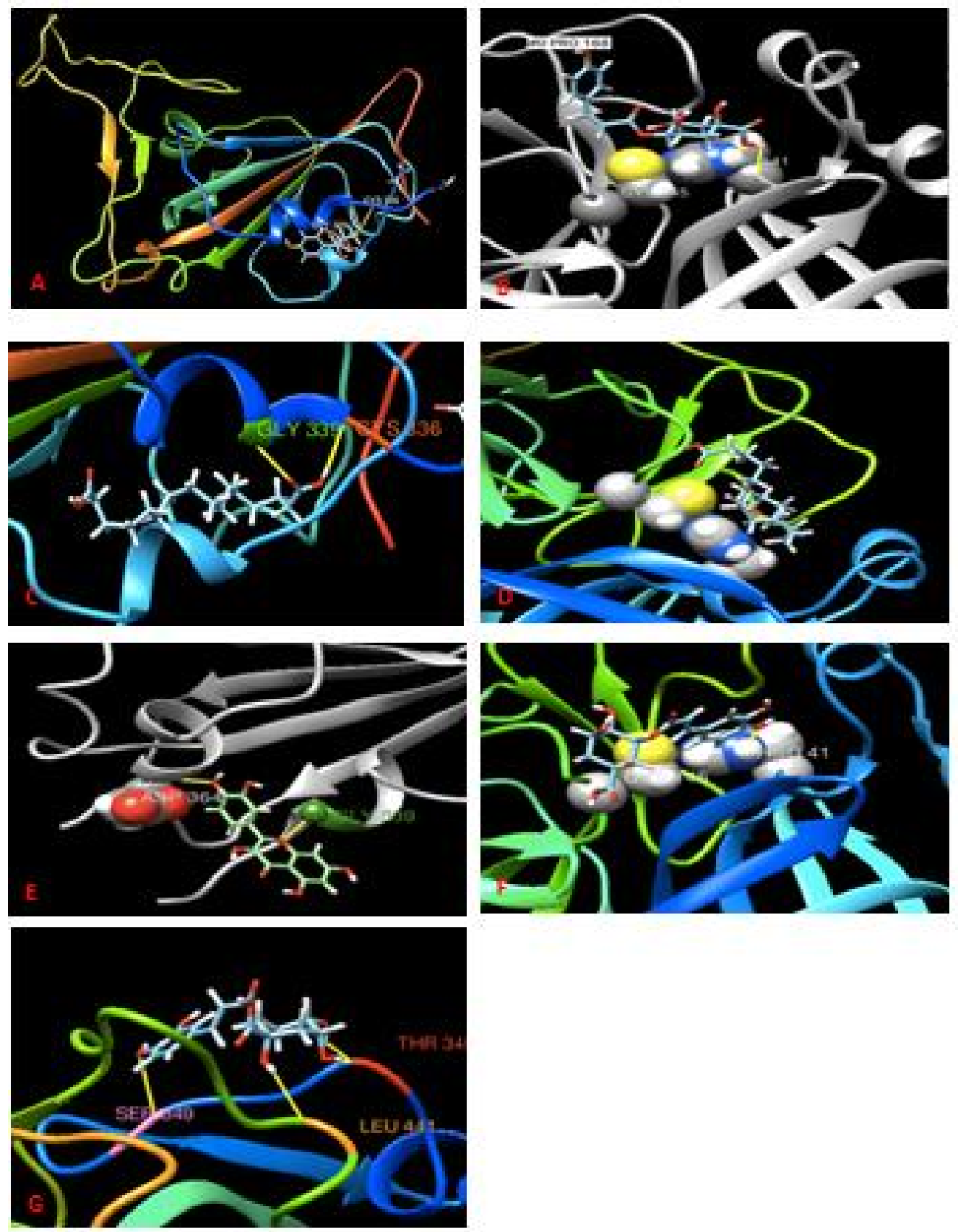

Fig. 3. Hydrogens bonds interactions (yellow solid lines) of ligands with both RBD site of virus spike protein (left side) and the activity site of SARS-COV2 main protease (Right side). A \& B: Coumarylquinic acid, C \& D: Hexadecanedioic acid, E \& F: Quercetin and G: Stigmasterol 

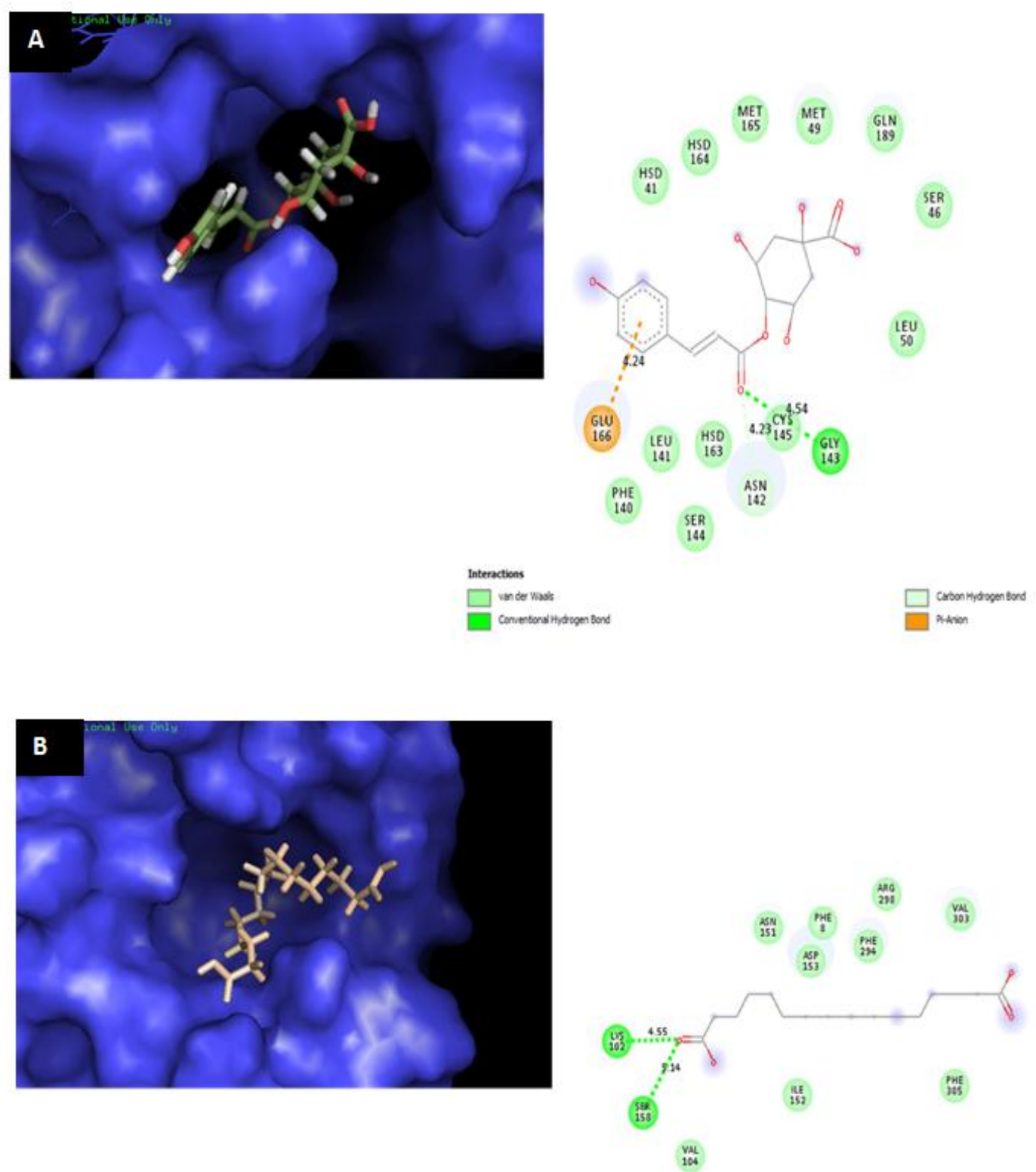

Fig. 4.1. The binding configuration of ligands showing their pose and interaction analyses in the binding site of the main protease of SARS-CoV-2. (a) Coumarylquinic, (b) Hexadecandioic acid. Interaction analysis in 2D was executed using discovery studio visualizer; it shows different types of non-covalent interactions between Ligands and the amino acid residues in the binding site of Mpro 

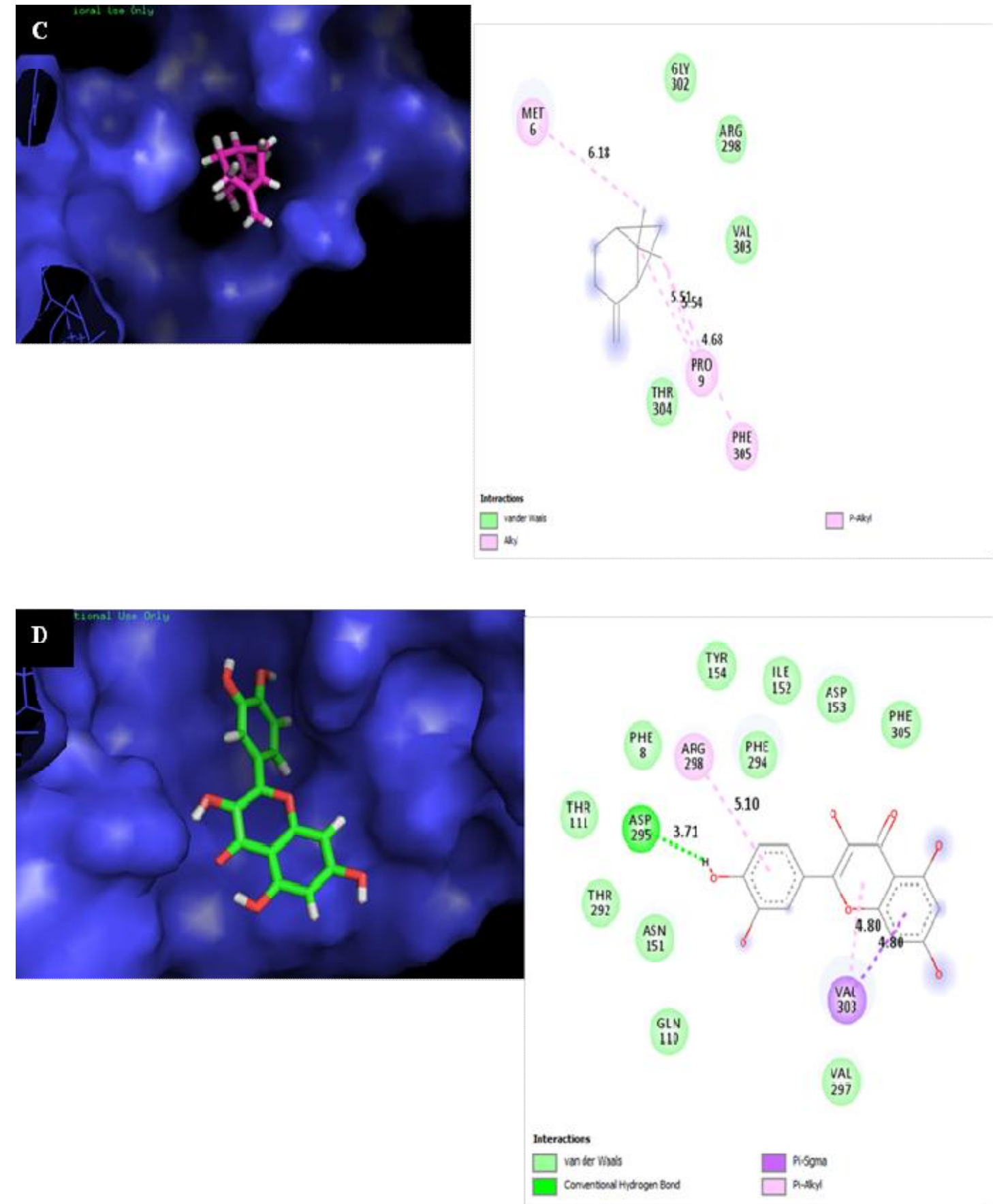

Fig. 4.2. The binding configuration of ligands showing their pose and interaction analyses in the binding site of the main protease of SARS-CoV-2. (c) Pinene, (d) quercetin. Interaction analysis in 2D was executed using discovery studio visualizer; it shows different types of noncovalent interactions between Ligands and the amino acid residues in the binding site of Mpro

In Table (2), ADMET test results showed that compounds with the highest negative docking energy (Coumarylquinic acid, Hexadecanedioic acid, Quercetin and Stigmasterol) have high OB that reflects the ability of compounds to enter the human circulatory system [35]. All tested molecules showed high permeability in the intestinal epithelial cells (Caco-2) which means 
high absorption of the drug [36]. All molecules appeared as drug-like with high potential to become drugs as compared with known drugs [37], except Hexadecanedioic acid with least potential. All molecules appeared with excellent $\mathrm{HL}$ (except for Hexadecanedioic acid the data is not available) that reflects drug therapeutic availability in the blood where dose, dosing intervals and volume of drug accumulation can be calculated [38,39]. Quercetin showed excellent $\mathrm{HL}$ and it was reported that it was $3.8 \mathrm{hr}$ for the distribution phase and $16.8 \mathrm{hr}$ for the elimination phase [40]. All herbs showed no hepatotoxicity and no toxicity in AMES test.
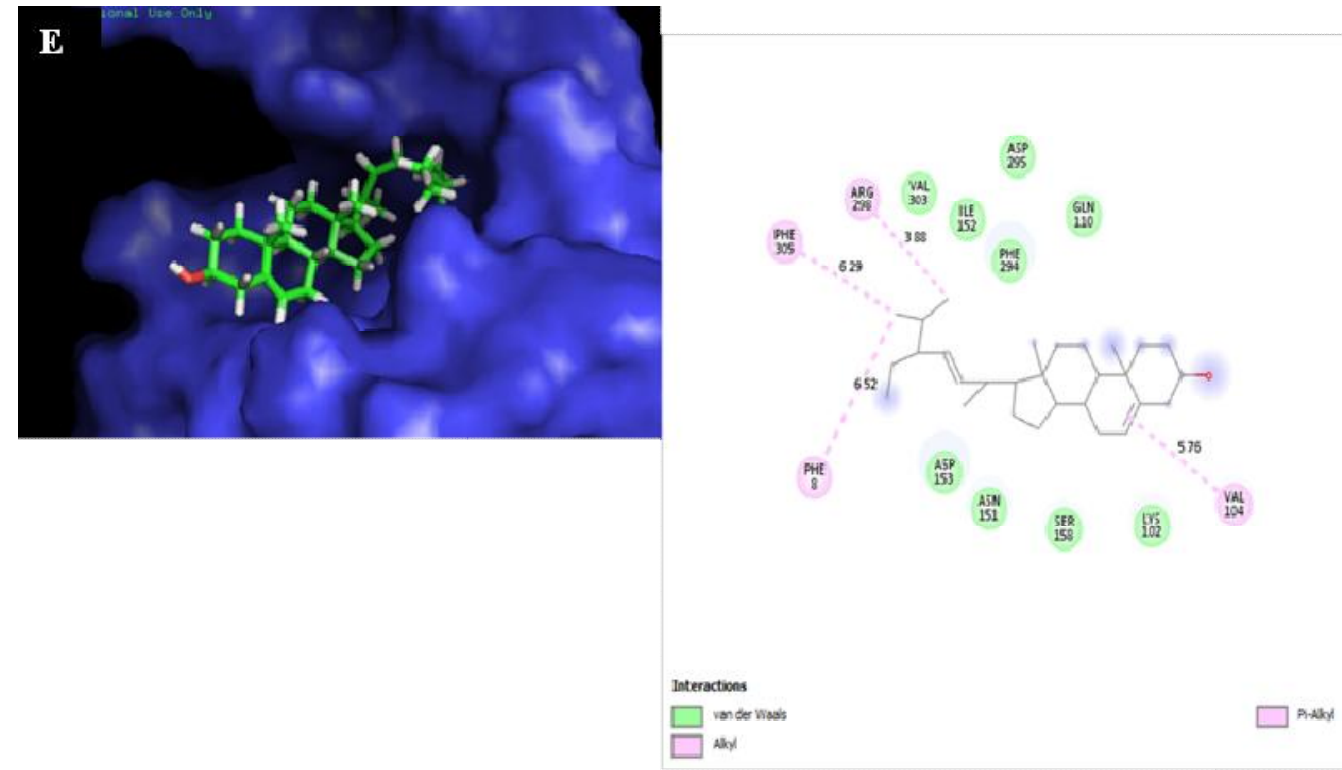

Fig. 4.3. The binding configuration of ligands showing their pose and interaction analyses in the binding site of the main protease of SARS-CoV-2., (E) stigmasterol. Interaction analysis in 2D was executed using discovery studio visualizer; it shows different types of non-covalent interactions between Ligands and the amino acid residues in the binding site of Mpro
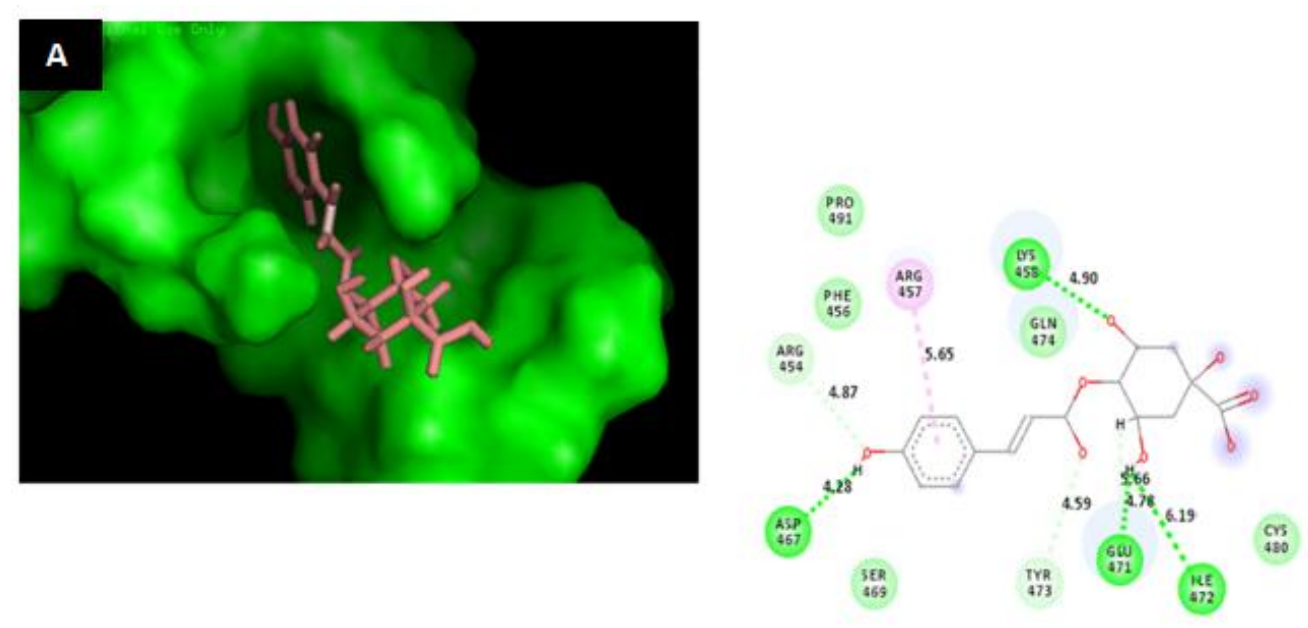

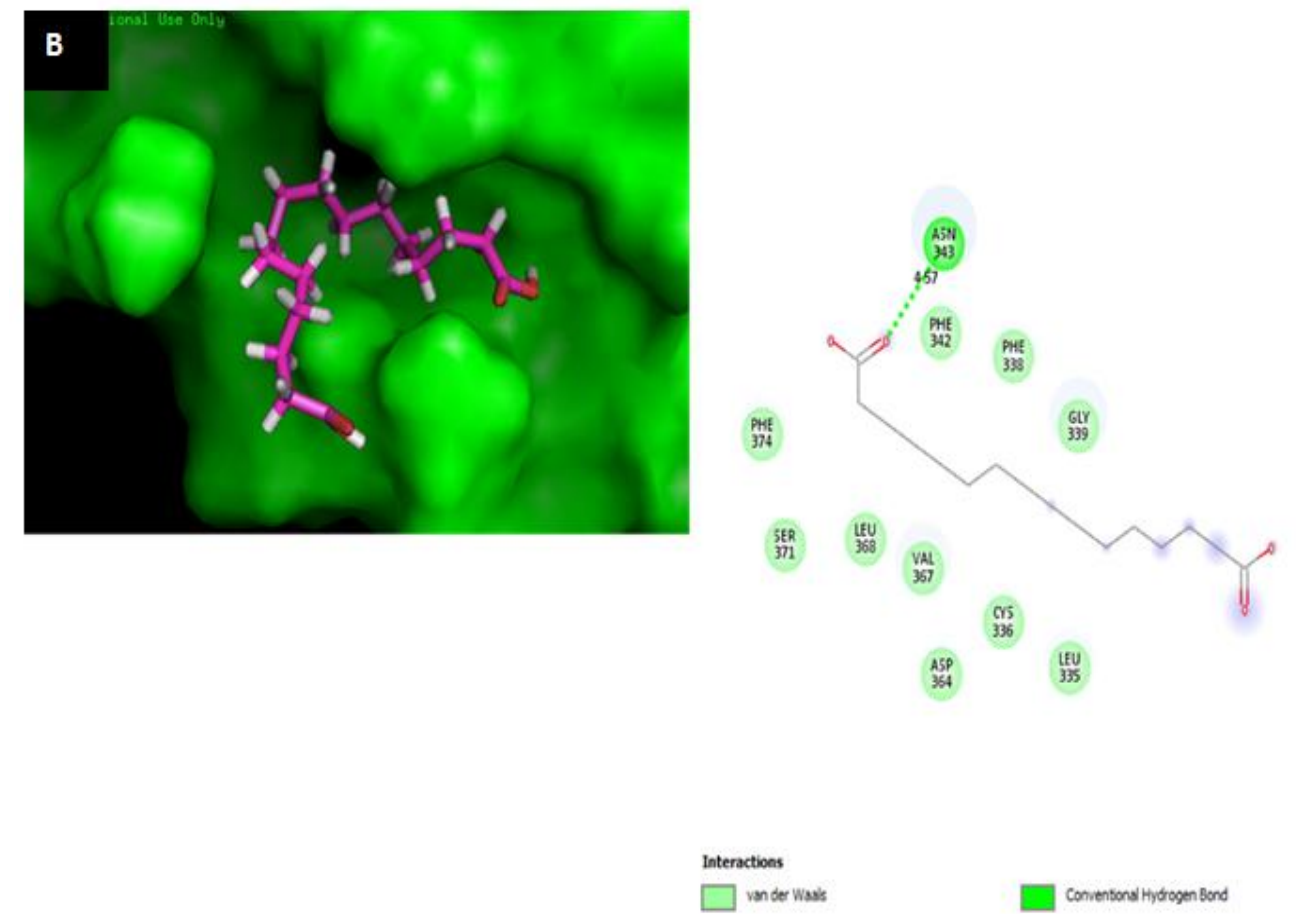

Fig. 5.1. The binding configuration of ligands showing their pose and interaction analyses in the binding site of the RBD of SARS-CoV-2. (a) Coumarylquinic and (b) Hexadecandioic acid. Interaction analysis in 2D was executed using discovery studio visualizer; it shows different types of non-covalent interactions between Ligands and the amino acid residues in the binding site of spike protein's RBD
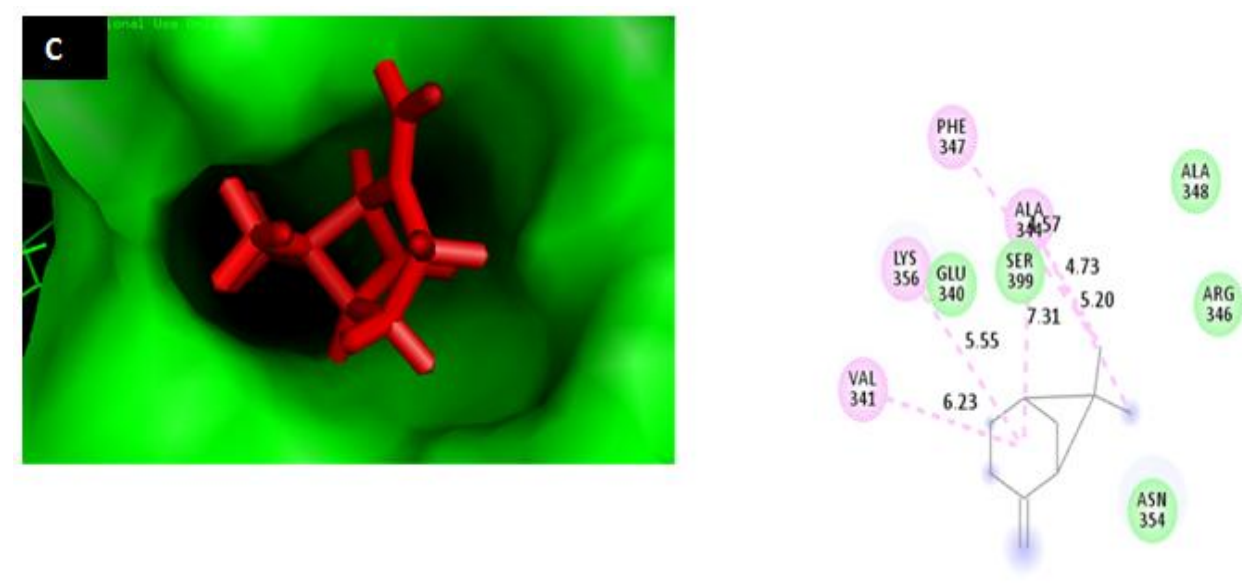

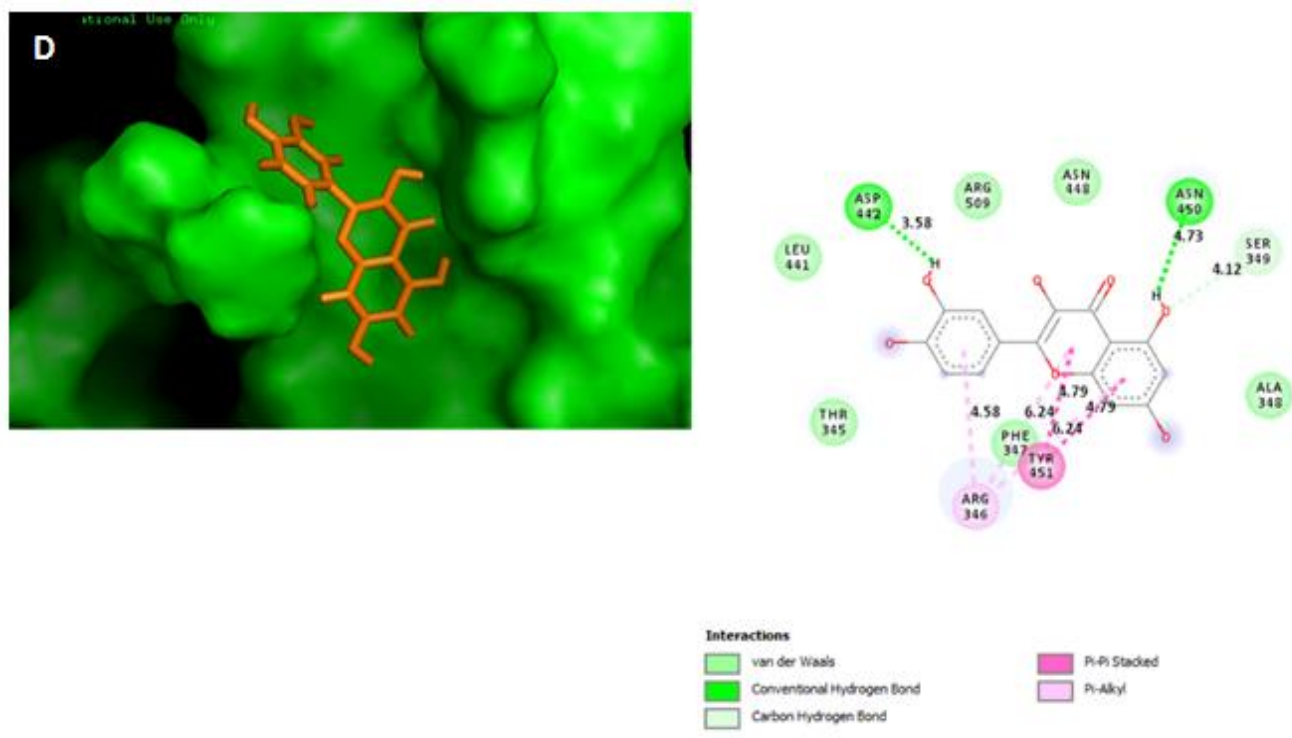

Fig. 5.2. The binding configuration of ligands showing their pose and interaction analyses in the binding site of the RBD of SARS-CoV-2. (c) Pinene and (d) quercetin. Interaction analysis in 2D was executed using discovery studio visualizer; it shows different types of non-covalent interactions between Ligands and the amino acid residues in the binding site of spike protein's RBD
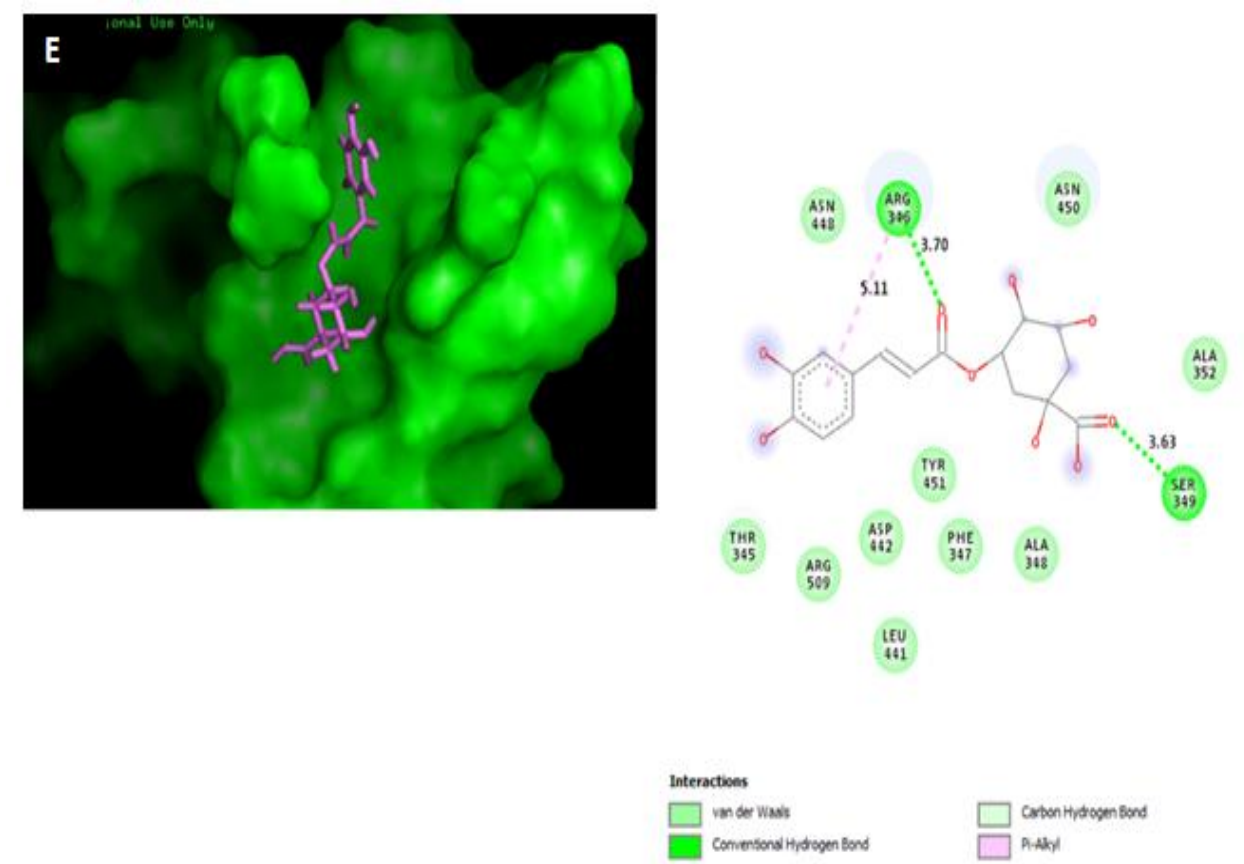

Fig. 5.3. The binding configuration of ligands showing their pose and interaction analyses in the binding site of the RBD of SARS-CoV-2. (E) stigmasterol. Interaction analysis in 2D was executed using discovery studio visualizer; it shows different types of non-covalent interactions between Ligands and the amino acid residues in the binding site of spike protein's RBD 
Table 1. Compounds used in docking against spike protein and main protease of SARS-COV2 with their binding energy

\begin{tabular}{lllll}
\hline Molecule & \multicolumn{2}{c}{ Spike protein (RBD) } & Mpro \\
\cline { 2 - 5 } & $\begin{array}{l}\Delta \text { G energy } \\
\text { Kcal/mol }\end{array}$ & $\begin{array}{l}\text { Fullfitness } \\
\text { energy Kcal/mol }\end{array}$ & $\begin{array}{l}\Delta \text { G energy } \\
\text { Kcal/mol }\end{array}$ & $\begin{array}{l}\text { Fullfitness energy } \\
\text { Kcal/mol }\end{array}$ \\
\hline Coumarylquinic acid & -7.349 & -777.302 & -6.790 & -1062.204 \\
Hexadecanedioic & -7.727 & -874.620 & -7.663 & -1317.67 \\
acid & & & & \\
Quercetin & -7.235 & -780.665 & -6.697 & -1078.491 \\
Stigmasterol & -7.195 & -770.540 & -7.845 & -1060.826 \\
Beta Pinene & -6.077 & -737.554 & -5.918 & -1031.781 \\
Camphene & -5.903 & -575.211 & -6.016 & -1072.217 \\
Cymene & -5.935 & -794.086 & -5.772 & -1086.974 \\
Eucalyptol & -6.373 & -789.774 & -5.929 & -1083.707 \\
Neoclovene & -6.511 & -750.804 & -6.631 & -1048.018 \\
Alpha-phellandrene & -6.024 & -799.523 & -5.918 & -1094.087 \\
Spathulenol & -6.527 & -549.871 & -6.171 & -847.305 \\
Vanillin & -6.030 & -785.173 & -5.913 & -1080.240 \\
Chlorogenic & -7.524 & -773.538 & -7.236 & -1053.588 \\
\hline
\end{tabular}

Table 2. Pharmacokinetic properties of the tested molecules

\begin{tabular}{llllll}
\hline Molecule & \multicolumn{5}{c}{ Pharmacokinetic properties } \\
\cline { 2 - 6 } & OB (\%) & Caco-2 & DL & HL (h) & T \\
\hline Coumaroylquinic acid & 37.63 & -0.656 & 0.29 & 5.15 & No \\
Hexadecanedioic acid & 20.72 & 0.301 & 0.16 & - & No \\
Quercetin & 46.43 & 0.05 & 0.28 & 14.40 & No \\
Stigmasterol & 43.83 & 1.44 & 0.76 & 5.57 & No \\
\hline
\end{tabular}

\section{DISCUSSION}

Many current studies have applied molecular docking to predict some suitable inhibitors for COVID-19 entry and replication, one study has tested mixture of herbs, antiviral drugs and other drugs against SARS-COV2 main protease, high free energy values resulted from docking proved that these compounds are really bind with Mpro active site leading to protein inhibition [41]. Coumarylquinic acid is an ester derivative of quinic acid that is found in many foods, researchers have found that quinic acid derivatives exhibit anti- inflammatory properties both in vivo and in vitro, and for that consider as good therapeutic targets for viral infections, furthermore, some of quinic amides have prevent Dengue virus infections in Huh 7.5 cells at different infection levels [42]. Coumaroylquinic acid has been proved as hepatoprotective and anti-hepatitis $B$ virus (HBV) that reduced the extracellular HBV DNA level significantly [43] and against other respiratory viruses [44]. Our docking results also showed another promising inhibitor of both SARS-COV2 spike protein and Mpro, Hexadecanedioic acid free energy binding with RBD site was -7.727 and with Mpro was -
7.663. Higher negative Gibbs energy, means more favorable complex binding and reaction shifting into equilibrium state [45]. Hexadecanedioic acid has been reported as antithrombotic and atherosclerosis agent through its activity on the clotting system at the platelet, fibrinogen or Fibrinolysis levels in plasma [46, 47]. Quercetin and Stigmasterol showed the best Pharmacokinetic Properties among other tested molecules where Quercetin has the best $\mathrm{OB}$ and HL while Stigmasterol has better Caco-2.

The flavonoid Quercetin is represented as a drug and dietary supplement that has beneficial effects in Chronic Obstructive Pulmonary Disease (COPD) that is significantly decreased lung inflammation and prevented progression [48]. Quercetin was reported to inhibit tumor necrosis factor-alpha (TNF- $\alpha$ ) overproduction and attenuate pathophysiological conditions during acute and chronic inflammation especially in respiratory conditions [49]. It showed antiviral activity that inhibits rhinovirus replication in vitro and in vivo [50], inhibits hepatitis C viral production in tissue culture through its inhibition of heat shock protein expression [51]. It has been shown to prevent platelet aggregation, lower the 
plasma lipid, lipoprotein and hepatic cholesterol levels, induced endothelium-dependent vasorelaxation via increase nitric oxide production. Quercetin and its glycosides were also reported to inhibit the angiotensin-converting enzyme activity [48]. It is highly safe and reported no evidence of in vivo toxicity, including lack of genotoxic/carcinogenic properties and Generally Recognized as Safe (GRAS) by The FDA $[52,53]$.

Stigmasterol is a steroid derivative represented as natural preventive dietary product and was reported as a useful adjunctive therapy for hypercholesterolemic patients where plasma total cholesterol and LDL-C concentrations were significantly reduced [54].

\section{CONCLUSION}

Study results explained the potential activity of some herbs in blocking new coronavirus spike protein and main protease that result in virus inhibition at entry and replication levels, coumarylquinic acid shows this ability in silico, further confirmative studies are needed to test compound inhibition ability in cell line culture, stigmasterol has strong binding with RBD site of spike protein, both compounds have safe pharmacophore properties to be used as a combination therapy to treat SARS-COV2 infections.

\section{COMPETING INTERESTS}

Authors have declared that no competing interests exist.

\section{REFERENCES}

1. Worldometer. Countries where COVID-19 has spread; 2020. Accessed 31 July 2020. Available:https://www.worldometers.info/co ronavirus/countries-where-coronavirushas-spread/.

2. World Health Organization. Statement on the second meeting of the International Health Regulations (2005) Emergency Committee regarding the outbreak of novel coronavirus (2019-nCoV); 2020. Accessed 31 July 2020.

Available:https://www.who.int/newsroom/detail/30-01-2020-statement-on-thesecond-meeting-of-the-internationalhealth-regulations-(2005)-emergencycommittee-regarding-the-outbreak-ofnovel-coronavirus-(2019-ncov).
3. Chen Z, Nakamura T. Statistical evidence for the usefulness of Chinese medicine in the treatment of SARS. Phytother Res 2004;18(7):592-4.

4. Lai L, Han $X$, Chen $H$, Wei $P$, Huang $C$, Liu $S$, et al. Quaternary structure, substrate selectivity and inhibitor design for SARS 3C-like proteinase. Cur Pharm Des. 2006;12(35):4555-64.

5. Wang SQ, Du QS, Zhao K, Li AX, Wei DQ, Chou KC. Virtual screening for finding natural inhibitor against cathepsin- $L$ for SARS therapy. Amino Acids. 2007;33(1):129-35.

6. Kesel AJ. Synthesis of novel test compounds for antiviral chemotherapy of severe acute respiratory syndrome (SARS). Curr Med Chem. 2005;12(18):2095-162.

7. Wu CY, Jan JT, Ma SH, Kuo CJ, Juan HF, Cheng YS, et al. Small molecules targeting severe acute respiratory syndrome human coronavirus. Proc Natl Acad Sci U S A. 2004;101(27):10012-7.

8. Liu B, Zhou J. SARS-CoV protease inhibitors design using virtual screening method from natural products libraries. J Comput Chem. 2005;26(5):484-90.

9. Hoever G, Baltina L, Michaelis M, Kondratenko R, Baltina L, Tolstikov GA, et al. Antiviral activity of glycyrrhizic acid derivatives against SARS-coronavirus. J Med Chem. 2005;48(4):1256-9.

10. Li SY, Chen C, Zhang HQ, Guo HY, Wang $H$, Wang $L$, et al. Identification of natural compounds with antiviral activities against SARS-associated coronavirus. Antiviral Res. 2005;67(1):18-23.

11. Xu X, Chen P, Wang J, Feng J, Zhou H, Li $X$, et al. Evolution of the novel coronavirus from the ongoing Wuhan outbreak and modeling of its spike protein for risk of human transmission. Sci China Life Sci. 2020;63(3):457-60.

12. Mukherjee $P$, Shah F, Desai P, Avery M. Inhibitors of SARS-3CLpro: virtual screening, biological evaluation, and molecular dynamics simulation studies. J Chem Inf Model. 2011;51(6):1376-92.

13. Durán F, Alonso N, Caamaño O, GarcíaMera X, Yañez M, Prado-Prado FJ, et al. Prediction of Multi-Target Networks of Neuroprotective Compounds with Entropy Indices and Synthesis, Assay, and Theoretical Study of New Asymmetric 1,2Rasagiline Carbamates. Int. J. Mol. Sci. 2014;15:17035-64. 
14. González-Díaz H, Herrera-lbatá DM, Duardo-Sánchez A, Munteanu CR, Orbegozo-Medina RA, Pazos A. ANN multiscale model of anti-HIV Drugs activity vs AIDS prevalence in the US at county level based on information indices of molecular graphs and social networks. J Chem Inf Model. 2014;54(3):744-55.

15. Romero-Durán FJ, Alonso $N$, Yañez $M$, Caamaño O, García-Mera X, GonzálezDíaz H. Brain-inspired cheminformatics of drug-target brain interactome, synthesis, and assay of TVP1022 derivatives. Neuropharmacology. 2016;103:270-8.

16. Lei $Q$, Liu $H$, Peng $Y$, Xiao $P$. In silico target fishing and pharmacological profiling for the isoquinoline alkaloids of Macleaya cordata (Bo Luo Hui). Chinese Medicine. 2015;10:37.

17. Ma X, Lv B, Li P, Jiang X, Zhou Q, Wang X, Gao X (2016) Identification of multiple components-multiple targets-multiple pathways associated with Naoxintong capsule in the treatment of heart diseases using UPLC/Q-TOF-MS and network pharmacology. Evid Based Complement Alternat Med. 2016;1-15.

18. Shao Y, Qiao L, Wu L, Sun X, Zhu D, Yang, $X$, et al. Structure identification and anti-cancer pharmacological prediction of triterpenes from ganoderma lucidum. Molecules. 2016;21:678.

19. Wen CC, Kuo YH, Jan JT, Liang PH, Wang SY, Liu HG, et al. Specific plant terpenoids and lignoids possess potent antiviral activities against severe acute respiratory syndrome coronavirus. J Med Chem. 2007;50(17):4087-95.

20. Ryu YB, Park SJ, Kim YM, Lee JY, Seo WD, Chang JS, et al. SARS-CoV 3CLpro inhibitory effects of quinone-methide triterpenes from Tripterygium regelii. Bioorg Med Chem Lett. 2010;20(6):18736.

21. Park JY, Kim JH, Kim YM, Jeong HJ, Kim DW, Park KH, et al. Tanshinones as selective and slow-binding inhibitors for SARS-CoV cysteine proteases. Bioorg Med Chem. 2012;20(19):5928-35.

22. Park JY, Kim JH, Kwon JM, Kwon HJ, Jeong HJ, Kim YM, et al. Dieckol, a SARS$\mathrm{CoV} 3 \mathrm{CL}$ (pro) inhibitor, isolated from the edible brown algae Ecklonia cava. Bioorg Med Chem. 2013;21(13):3730-7.

23. Song YH, Kim DW, Curtis-Long MJ, Yuk HJ, Wang Y, Zhuang N, et al. Papain-like protease (PLpro) inhibitory effects of cinnamic amides from Tribulus terrestris fruits. Biol Pharm Bull. 2014;37(6):1021-8.

24. Park JY, Ko JA, Kim DW, Kim YM, Kwon $\mathrm{HJ}$, Jeong $\mathrm{HJ}$, et al. Chalcones isolated from Angelica keiskei inhibit cysteine proteases of SARS-CoV. J Enzyme Inhib Med Chem. 2016;31(1):23-30.

25. Shen L, Niu J, Wang C, Huang B, Wang W, Zhu N, et al. High-throughput screening and identification of potent broad-spectrum inhibitors of coronaviruses. $\mathrm{J}$ Virol. 2019;93(12):e00023-e119.

26. Hui DS, I Azhar E, Madani TA, Ntoumi F, Kock R, Dar O, et al. The continuing 2019$\mathrm{nCoV}$ epidemic threat of novel coronaviruses to global health - The latest 2019 novel coronavirus outbreak in Wuhan, China. Int $\mathrm{J}$ Infect Dis. 2020;91:264-66.

27. Zhou P, Yang XL, Wang XG, Hu B, Zhang $L$, Zhang $W$, et al. A pneumonia outbreak associated with a new coronavirus of probable bat origin. Nature. 2020;579(7798):270-73.

28. Tian Huaiyu. 2019-nCoV: New Challenges from Coronavirus[J/OL]. Chinese Journal of Preventive Medicine. 2020;54. online pre-publication.

DOI:10.3760/cma.j.issn.0253-

9624.2020.0001.

29. Kneller DW, Phillips G, O'Neill HM et al. Structural plasticity of SARS-CoV-2 3CL Mpro active site cavity revealed by room temperature X-ray crystallography. Nat Commun. 2020;11:3202.

30. Grosdidier A, Zoete V, Michielin O. SwissDock, a protein-small molecule docking web service based on EADock DSS. Nucleic Acids Res. 2011;39:W270W277.

31. Pettersen EF, Goddard TD, Huang CC, Couch GS, Greenblatt DM, Meng EC, Ferrin TE. UCSF Chimera-A visualization system for exploratory research and analysis. J Comput Chem. 2004;25(13):1605-12.

32. Pereira ASP, Bester MJ, Apostolides Z. Exploring the anti-proliferative activity of Pelargonium sidoides DC with in silico target identification and network pharmacology. Molecular Diversity. 2017;21(4):809-20.

33. Feixiong $C$, Weihua $L i$, Yadi $Z$, Jie $S$, Zengrui W, Guixia L, et al. admet SAR: a comprehensive source and free tool for evaluating chemical ADMET properties. J. Chem. Inf. Model. 2012;52(11):3099-3105. 
34. Hu W, Fu W, Wei X, Yang Y, Lu C, Liu Z. A network pharmacology study on the active ingredients and potential targets of Tripterygium wilfordii Hook for treatment of rheumatoid arthritis. Evid Based Complement Alternat Med. 2019;5276865.

35. Liang $\mathrm{X}$, Li $\mathrm{H}$, Li S. A novel network pharmacology approach to analyse traditional herbal formulae: the Liu-Wei-DiHuang pill as a case study. Mol Biosyst. 2014;10(5):1014-22.

36. Wu L, Wang $\mathrm{Y}$, and Fan $\mathrm{X}$. Tools for network pharmacology study: network visualization and network analysis. China Journal of Chinese Materia Medica. 2011;36(21):2923-25.

37. Zheng CS, Xu XJ, Ye HZ, Wu GW, Li XH, $\mathrm{Xu} \mathrm{HF}$, et al. Network pharmacologybased prediction of the multi-target capabilities of the compounds in Taohong Siwu decoction, and their application in osteoarthritis. Experimental and Therapeutic Medicine. 2013;6(1):125-32.

38. Tao W, Xu X, Wang X, Li B, Wang Y, Li Y, et. al. Network pharmacology-based prediction of the active ingredients and potential targets of Chinese herbal Radix Curcumae formula for application to cardiovascular disease. J Ethnopharmacol. 2013;145(1):1-10.

39. Yang $\mathrm{H}$, Zhang $\mathrm{W}$, Huang $\mathrm{C}$, Zhou W, Yao $Y$, Wang $Z$, et. al. A novel systems pharmacologymodel for herbalmedicine injection: a case using reduning injection. BMC Complementary and Alternative Medicine. 2014;14(1):430.

40. IARC. Monographs on the evaluation of the carcinogenic risk of chemicals to humans. geneva: world health organization, International Agency for Research on Cancer, 1972-PRESENT. (Multivolume work); 1999. Accessed 1 Aug 2020.

Available:http://monographs.iarc.fr/ENG/Cl assification/index.php, p. V73 P501.

41. Das $S$, Sarmah $S$, Lyndem $S$ \& Singha Roy: An investigation into the identification of potential inhibitors of SARS-CoV-2 main protease using molecular docking study, J Biomol Struct Dyn. 2020;1-11.

42. Zanello PR, Koishi AC, Rezende Júnior Cde O, Oliveira L, Pereira A, Almeida M, et al. Quinic acid derivatives inhibit dengue virus replication in vitro. Virol j. 2015;(12):223.

43. $\mathrm{Kim} \mathrm{KH}, \mathrm{Kim} \mathrm{YH}$, Lee KR. Isolation of quinic acid derivatives and flavonoids from the aerial parts of Lactuca indica $L$. and their hepatoprotective activity in vitro. Bioorg Med Chem Lett. 2007;17(24):673943.

44. Wei F, Ma SC, Ma LY, But PP, Lin RC \& Khan IA. Antiviral flavonoids from the seeds of Aesculus chinensis. Journal of natural products. 2004;67(4):650-53.

45. Perrot, Pierre. $A$ to $Z$ of Thermodynamics. Oxford University Press. ISBN 0-19856552-6; 1998.

46. Colli S, Sirtori CR. Drugs Affecting Thrombosis and Atherosclerosis. In: Catapano A.L., Gotto A.M., Smith L.C., Paoletti R. (eds) Drugs Affecting Lipid Metabolism. Medical Science Symposia Series.1993. vol 2. Springer, Dordrecht.

47. Margaglione M, Grandone E, Mancini FP, Di Minno G. Drugs affecting plasma fibrinogen levels. Implications for new antithrombotic strategies. In: Jucker $E$. (eds) Progress in Drug Research/Fortschritte der Arzneimittelforschung/Progrès des recherches pharmaceutiques. Progress in Drug Research/Fortschritte der Arzneimittelforschung/Progrès des recherches pharmaceutiques. 1996;46. Birkhäuser Basel.

48. Han MK, Barreto TA, Martinez FJ, Comstock AT, Sajjan US. Randomised clinical trial to determine the safety of quercetin supplementation in patients with chronic obstructive pulmonary disease. BMJ Open Respir Res. 2020;7(1)pii:e000392.

49. Coates PM, Blackman MR, Cragg GM, Levine $M$, Moss J, White JD. (Ed). Encyclopedia of dietary supplements. Marcel Dekker. New York, NY. 2005;580.

50. Ganesan S, Faris AN, Comstock AT, Wang Q, Nanua S, Hershenson MB, Sajjan US. Quercetin inhibits rhinovirus replication in vitro and in vivo. Antiviral Res. 2012;94(3):258-71.

51. Lu NT, Crespi CM, Liu NM, Vu JQ, Ahmadieh Y, Wu SF, et al. A Phase I. Dose escalation study demonstrates quercetin safety and explores potential for bioflavonoid antivirals in patients with chronic hepatitis C. Phytother Res. 2016;30(1):160-8.

52. Harwood M, Danielewska-Nikiel B, Borzelleca JF, Flamm GW, Williams GM, Lines TC. A critical review of the data related to the safety of quercetin and lack of evidence of in vivo 
toxicity, including lack of genotoxic/carcinogenic properties. Food Chem Toxicol. 2007;45(11):2179205.

53. Okamoto T. Safety of quercetin for clinical application (Review). Int $\mathrm{J}$ Mol Med. 2005;16(2):275-8.
54. Nigon F, Serfaty-Lacrosnière C, Beucler I, Chauvois D, Neveu C, Giral P, et al. Plant sterol-enriched margarine lowers plasma LDL in hyperlipidemic subjects with low cholesterol intake: effect of fibrate treatment. Clinical chemistry and laboratory medicine. 2001;39(7):634-40.

(c) 2020 Al-Jassani et al.; This is an Open Access article distributed under the terms of the Creative Commons Attribution License (http://creativecommons.org/licenses/by/4.0), which permits unrestricted use, distribution, and reproduction in any medium, provided the original work is properly cited.

Peer-review history:

The peer review history for this paper can be accessed here:

http://www.sdiarticle4.com/review-history/59980 